\title{
EDITORIAL
}

\section{Facilitating the dissemination of scientific information}

The National Science Foundation of Sri Lanka and its predecessors have promoted science and research in the country for the past 40 years. During this period the Foundation has developed many mechanisms for consolidating the national science and technology base in the country. The National Science Foundation has been instrumental in advancing the research capability of many scientists both at the national and international level. The new programmes initiated by the Foundation such as the coordinated Thematic Research Programme, overseas special training programme, on the job short term training in areas of high priority for national development, international linkages and the support services for these programmes have proved to be of immense value to advance S\&T in the country. The publication of a journal, in order to disseminate the findings of researchers is one such support service.

The Journal of the National Science Foundation had its origin in the National Science Council which published 2 issues per year. The inaugural issue of the publication (Vol. 1 - No.1) was in 1973. We record our grateful appreciation of the services of the first Editorial Board of 11 members chaired by Dr. G. C. N. Jayasuriya and all subsequent editorial boards which have rendered invaluable services.

The Journal continued to publish 2 issues per year up to 1993 . In 1994 the policy changed and the number of issues increased to 4 per year, a practice which has been continued to-date.

With the establishment of the National Science Foundation in 1998 the title of the Journal changed to Journal of the National Science Foundation of Sri Lanka.

2006 and 2008 have been landmark years in the progress of the Journal. The indexing of the Journal articles in Biosis Previews, Zoological Record and Biological Abstracts commenced with volume 34, No. 3 in 2006. This was followed by the Science Citation Index Expanded (also known as Scisearch) and Journal Citation Reports commencing the indexing of the Journal articles from Volume 36- No. 1 (2008).

The above was made possible by the committed work of the scientists contributing quality research articles to the Journal and the hard work of the staff of the National Science Foundation.

The Special Issue of the Journal celebrates the 40th year of service by the National Science Foundation and its predecessors to the advancement of science and technology in Sri Lanka. I congratulate and thank the scientists and the staff of the National Science Foundation who have contributed to this endeavour.

Nalini Ratnasiri 